\title{
entrevista
}

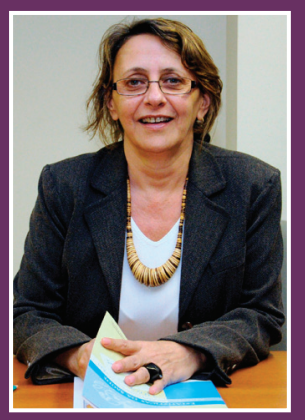

\section{WASMÁLIA BIVAR}

Por JosÉ RIBEIRo GUIMARÃEs

Entrevista realizada em

novembro de 2013.

Wasmália Bivar é Presidente do Instituto Brasileiro de Geografia e Estatística (IBGE) desde 2011. Graduada em Economia pela Pontifícia Universidade Católica do Rio de Janeiro (PUC-RJ), possui mestrado em Economia pela PUC e doutorado em Economia pela Università Commerciale Luigi Bocconi (Milão - Itália). Pesquisadora Titular no IBGE desde 1986, possui uma vasta experiência na área econômica, com ênfase na Economia do Trabalho. Atuou em estudos ligados a desemprego, economia do trabalho e duração do desemprego, além de participar do desenvolvimento de pesquisas estruturais e conjunturais de indústria, demografia de empresas, inovação tecnológica, bem como planejamento, execução e análise de pesquisas estatísticas sobre o segmento industrial.
O IBGE VEM REALIZANDO UM AMPLO PROCESSO DE REESTRUTURAÇÃO NO SEU SISTEMA DE PESOUUISAS ECONÔMICAS, SOCIAIS E DOMICILIARES. QUAIS AS MOTIVAÇÕES E BASE DESSES PROCESSOS? NA ÁREA SOCIAL, QUE NOVAS PESOUUISAS OU REFORMULAÇÕES ESTÃO SENDO REALIZADAS?

As mudanças no Sistema Estatístico Nacional (SEN) são para ampliar o conjunto de informações disponíveis para a sociedade brasileira, tanto as estatísticas disponíveis, como também as informações geocientíficas, pois é cada vez mais importante que a dimensão territorial esteja presente. As informações geocientíficas permitem análises integrando diferentes dimensões do território. As mudanças que estamos fazendo no sistema de informação, especialmente as estatísticas, dizem respeito a buscar atender as crescentes demandas nacionais. São crescentes não só em termos de incorporar novos temas, mas também as necessidades de ampliação de cobertura territorial e de regularizar a investigação de temas que já são conhecidos. 
Esse processo deriva basicamente das transformações pelas quais passa a sociedade brasileira. Existe o movimento de consolidação da democracia brasileira, o movimento de transformações na área social, na área demográfica, na área ambiental e na área econômica. Todas essas transformações demandam informação. E é normal que assim seja. Tanto o gestor público quanto os agentes privados precisam de informação para que suas ações sejam baseadas em evidências. E para isso é preciso que os sistemas estatísticos atendam às demandas. Num país como o nosso, que tem se transformado tão forte e rapidamente, essas demandas, obviamente, são crescentes. E o que o IBGE está fazendo? Na década de 1990 nós reestruturamos as estatísticas econômicas. Hoje, elas passam por um processo de atualização, revisão e modernização, mas não há mudança de modelo. No caso das estatísticas domiciliares, que é onde se centra a maior parte das informações de natureza social e demográfica, o sistema atual teve sua origem há mais de 40 anos. Este sistema é da quando época na qual se iniciou a Pesquisa Nacional por Amostra de Domicílios (PNAD). A partir dela, na década de 1980, surgiram a Pesquisa Mensal de Emprego (PME) e a Pesquisa de Orçamentos Familiares (POF), a qual inicialmente tinha um caráter atualizador do índice de preço e depois passou a ser também uma pesquisa de grande interesse social, usando o consumo como um importante tema, no qual derivaram importantes indicadores sociais.

Tratam-se de pesquisas isoladas, que não são vistas de forma integrada, pois o IBGE opera até hoje um sistema de pesquisas independentes. Desde que assumi a Diretoria de Pesquisas, por volta do ano de 2004, tomei conhecimento da possibilidade de se montar um outro sistema. Técnica e metodologicamente existiam avanços que permitiam integrar as pesquisas domiciliares, criar uma estrutura 
única, fazer uma gestão muito mais eficiente, gerando mais informação com o mesmo esforço ou com um esforço pouco maior. Uma de nossas principais lacunas é a de não dispor de informação de curto prazo de mercado de trabalho, pois nós só temos as seis principais regiões metropolitanas cobertas pela PME e que abarcam 25\% da população economicamente ativa, o que é uma limitação muito grande. Outra questão é que tínhamos um grande veículo para transportar toda a demanda que a área social do país gera, que é a PNAD. Entretanto, a PNAD é realizada uma vez por ano. Essa limitação é dada. Existem temas que, simplesmente por existir um único veículo, precisam esperar muito mais tempo do que é requerido para acompanhar a sua evolução. A outra pesquisa de cobertura nacional, que é a Pesquisa de Orçamentos Familiares, também assume a função de veículo, mas a sua limitação é ainda maior, pois somente é realizada a cada cinco anos.
Diante deste contexto, concebemos, então, esse novo sistema. E como é esse novo sistema? Ele é composto por dois núcleos. Um núcleo refere-se à produção de informações de mercado de trabalho a curto prazo, no qual serão produzidas medidas de curto prazo e com cobertura nacional, incluindo-se as 27 unidades federativas e as regiões metropolitanas que incluem os municípios das capitais. Nós denominamos a pesquisa com esse foco de PNAD Contínua, pois não podemos abandonar essa marca. A PNAD Contínua está em campo, e nós divulgaremos seus primeiros resultados no início de 2014. A consolidação da PNAD Contínua é um grande esforço que - IBGE fez, mantendo todas as suas pesquisas e, ao mesmo tempo, realizando a PNAD Contínua, que vai produzir informações de natureza conjuntural com uma cobertura - em termos de território - maior do que a PNAD. Enquanto que a PNAD cobre cerca de 1.100 municípios, 
a PNAD Contínua abarca 3.400 municípios. Com uma melhor cobertura do território nacional, ela vai ser uma medida inequivocamente nacional. A PNAD Contínua é esse núcleo que vai servir de veículo para produção de informação de outras naturezas. O outro núcleo refere-se à Pesquisa de Orçamentos Familiares (POF), que, nos moldes atuais, é feita a cada cinco anos - o que chamamos de POF completa. Um passo muito importante que pretendemos dar no próximo ano é, a partir dessa POF completa, desenhar um esquema de pesquisa de orçamentos familiares simplificada, que possa ser acompanhada anualmente. Essa pesquisa tem importância não só do ponto de vista social, dado que o consumo é uma medida de bem-estar importante e mais facilmente captável do que a renda, mas também do ponto de vista econômico, pois teremos um componente do PIB brasileiro - o consumo das famílias - acompanhado de forma regular a cada ano por uma medida direta.
Acreditamos que esse sistema substituirá as atuais pesquisas. Enquanto isso, nós continuamos com essas pesquisas em paralelo até que possam ser abandonadas. Isso significa um esforço enorme para o IBGE, especialmente neste momento de escassez de recursos humanos. Mas o esforço que estamos fazendo na implementação desse sistema será bastante compensado pelas informações que essas pesquisas irão gerar e pela implementação de uma infraestrutura que fará coleta no Brasil inteiro com uma amostra completa a cada três meses. Isso nos dará a possibilidade de combinar temáticas e de introduzir temas mais amplos tanto na PNAD Contínua quanto no sistema de POFs contínuas que nos interessa implementar.

Isso vem associado a outras pesquisas que são demandas importantes. No final de 2013 nós estamos fechando a Pesquisa Nacional de Saúde (PNS), que é absolutamente inédita, pois trará 
informações socioeconômicas demográficas tradicionais combinadas com medidas antropométricas e outras medidas, como, por exemplo, circunferência abdominal, exames de sangue e urina, pressão arterial. Desse modo, se poderá traçar um quadro das condições de saúde no que diz respeito à incidência de doenças crônicas e a prevalência dessas doenças com as características socioeconômicas da população, o que pode resultar em ações muito mais efetivas dos gestores da área de saúde. Outra pesquisa importante que o IBGE vem realizando também com o Ministério da Saúde diz respeito ao tema dos jovens escolares. Pela segunda vez, investigamos junto aos jovens do $9^{\circ}$ ano do ensino fundamental vários hábitos de alimentação, esporte, saúde sexual reprodutiva, uso de fumo, álcool, drogas e comportamento que diz respeito à violência. Na própria PNAD nós temos avançado muito em vários temas, como segurança alimentar e educação profissional. O volume de informações produzidas por esse sistema, que já é muito grande, vai crescer ainda mais.

DENTRO DESSA LINHA, A SENHORA FEZ UM COMENTÁRIO IMPORTANTE QUE É O DE MANTER PARALELAS AS PESOUISAS REGULARES ENOUANTO ESSE SISTEMA ESTÁ SENDO IMPLANTADO. EM 2014, COM A PNAD CONTÍNUA JÁ IMPLANTADA, COMO FICARIAM TEMAS COMO HABITAÇÃO E TRABALHO INFANTIL, OUE FAZEM PARTE DA PNAD ATUALMENTE E OUE A PRINCÍPIO NÃO SERÃO IMEDIATAMENTE INCORPORADAS NA PNAD CONTÍNUA?

Justamente neste momento estamos nessa grande discussão. Para não realizar as pesquisas no modelo antigo, é preciso que regularizemos a produção da PNAD Contínua no tema mercado de trabalho. Alcançado isso, completar o desenho. Hoje pensamos que alguns temas são mais interessantes de serem 
associados a uma pesquisa de orçamentos familiares, como, por exemplo, habitação, do que a uma pesquisa cujo foco é o mercado de trabalho. O trabatho infantil, por outro lado, não, pois vamos justamente aproveitar o fato da pesquisa contínua se fazer presente o ano inteiro em campo e melhorar a cobertura e mensuração do trabalho infantil, uma vez que ele se concentra muito nas atividades agropecuárias, que são sazonais - atualmente, com a PNAD, dispomos apenas de uma aferição pontual na semana de referência em setembro de cada ano.

Mesmo com a divulgação dos primeiros resultados da PNAD Contínua, a continuidade de algumas pesquisas em paralelo será o investimento que temos que continuar realizando. $\mathrm{O}$ abandono do modelo antigo vai depender dessa negociação, da nossa capacidade de avançar e negociar com os usuários esse salto.
UM DOS GRANDES MÉRITOS DO PROCESSO DE REFORMULAÇÃO DAS PESOUISAS DOMICILIARES DO IBGE VEM SENDO A REALIZAÇÃO PERIÓDICA DE FÓRUNS DE CONSULTA AOS USUÁRIOS. ESTA EXPERIÊNCIA BEM- SUCEDIDA NO ÂMBITO DO Sistema Integrado de Pesouisas DOMICILIARES (SIPD) PODERÁ SER ESTENDIDA A OUTRAS INICIATIVAS DO GÊNERO?

Esse deve ser o modelo. As transformações que afetaram - Brasil afetaram todo o país, inclusive o próprio IBGE. A conversa e consulta aos usuários, a identificação da demanda, a orientação e a concepção são feitas por meio de fóruns nos quais a interlocução com os usuários, os produtores, os especialistas, os acadêmicos, os formuladores de políticas enriquece o trabalho do IBGE. Esse processo de abertura coincide com o processo de democratização do país como um todo, e o IBGE abre ainda mais as suas portas para atender da melhor forma possível a sociedade brasileira. 
AO LONGO DAS DUAS ÚLTIMAS DÉCADAS A PRODUÇÃO DE ESTATÍSTICAS SOCIAIS OFICIAIS SE AMPLIOU E DIVERSIFICOU CONSIDERAVELMENTE NO BRASIL, SOBRETUDO POR INTERMÉDIO DOS REGISTROS ADMINISTRATIVOS PÚBLICOS, EM DISTINTAS ESFERAS ADMINISTRATIVAS. NA CONDIÇÃO DE COORDENADOR DO SISTEMA EstaTístico NACIONAL, COMO O IBGE VEM ATUANDO NESTE CONTEXTO?

O IBGE tem o mandato da coordenação. Tem a lei que diz que o IBGE é o produtor oficial e que coordena o Sistema Estatístico Nacional. Mas nada se faz por decreto. Acredito que o interesse nacional pelas informações, o reconhecimento do IBGE como um centro de competência técnica na produção das informações e essa necessidade das ações públicas serem baseadas em evidências têm feito com que todos se interessem em processos coordenados. Ninguém quer ser uma ilha. Todo mundo quer informações que possam ser cruzadas para ampliar seu horizonte de análise. Nesse contexto, nós tivemos um avanço institucional muito importante com a criação do Comitê de Estatística Sociais. Nele, tem assento todos os ministérios da área social e alguns órgãos, como o Instituto Nacional de Estudos e Pesquisas Educacionais Anísio Teixeira (INEP) e o Institutro de Pesquisa Econômica Aplicada (IPEA). Com isso, começamos a fazer o processo de articulação de forma mais sistemática e mais institucionalizada. A importância disso é que todos reconhecem a necessidade de instâncias dessa natureza para que se possa tirar proveito de toda a infraestrutura de informações que o país tem. Os registros administrativos são uma fonte preciosíssima e, à medida em que eles amadurecem e se reforçam vão desonerando a produção estatística, permitindo a ela se diversificar. Estamos prestes a criar um mesmo comitê na área econômica. 
TODA ESSA CULTURA DO BOM USO DAS ESTATÍSTICAS PARA TOMADA DE DECISÃO VEM PERMITINDO, JUNTO COM A ELABORAÇÃO DE BOAS POLÍTICAS, ATENUAR PROBLEMAS SOCIAIS HISTÓRICOS E ESPECÍFICOS. OBSERVAMOS, POR EXEMPLO, A DIMINUIÇÃO DA POBREZA, A OUUEDA DO DESEMPREGO E A REDUÇÃO DO TRABALHO INFANTIL. POR OUTRO LADO, A AMPLIAÇÃO DA BASE DE CONHECIMENTO PARA A ERRADICAÇÃO E/OU CONTINUIDADE DA MITIGAÇÃO DESTES PROBLEMAS REQUER A PRODUÇÃO DE ESTATÍSTICAS CADA VEZ MAIS DETALHADAS E COM MAIOR RAPIDEZ DE DIVULGAÇÃO. COMO CONCILIAR A PRODUÇÃO DE MAIS E MELHORES ESTATÍSTICAS COM A RESTRIÇÃO DOS RECURSOS DISPONÍVEIS, ALÉM DE EVITAR A SOBRECARGA E A EXAUSTÃO JUNTO À POPULAÇÃO RESPONDENTE DAS PESOUISAS?

Acredito que nós vamos evoluir. Hoje nós vivemos um bom momento de fortalecimento dos registros administrativos. Isso é importante à medida em que eles vão desonerando a produção estatística, conforme mencionei anteriormente. Por outro lado, na questão da cobertura geográfica, com um país dessa dimensão, é importante que fa- çamos aproximações com os órgãos estaduais de estatísticas, de planejamento e de estudos. Nós já temos um projeto nessa área há muitos anos que são as contas regionais e as contas estaduais. Queremos ampliar isso para a área de demografia. No caso das estatísticas, nós temos um projeto que os estados estão fortemente interessados, que é um estudo que define categorias territoriais. É preciso ter essa categorização melhor do que se tem hoje. Hoje temos a micro e mesorregiões geográficas, que estão paradas na década de 1980 ainda, com uma conformação que não adere mais à realidade. Queremos trabalhar isso conjuntamente com os estados para que tenhamos avanços nessa área. Afinal de contas, na sigla do IBGE, O " $G$ " se referea à geografia. E o "G" é muito importante nos dias de hoje, pois tem muita relação com a gestão do território, com a gestão do meio ambiente, com a questão dos impactos 
locais, das políticas nacionais. Toda essa demanda converge para o "G" do IBGE. E felizmente, o Brasil tem a singularidade de ter, num mesmo instituto, a geociência, a cartografia e os recursos naturais casados com as estatísticas.

Observa-se oue aO longo dos ÚLTIMOS ANOS O IBGE AMPLIOU CONSIDERAVELMENTE A SUA ATUAÇÃO E COOPERAÇÃO NO PLANO INTERNACIONAL. AlÉM DE GANHAR DIVERSOS PRÊMIOS NO EXTERIOR PELA REALIZAÇÃO DE PESOUUISAS INOVADORAS E PRESTAR ASSISTÊNCIA TÉCNICA A PAÍSES EM DESENVOLVIMENTO, A INSTITUIÇÃO VEM ORGANIZANDO E SEDIANDO INÚMEROS EVENTOS DE RELEVÂNCIA INTERNACIONAL. ADEMAIS, TEM OCUPADO POSIÇÕES DE DESTAQUE NO ÂMBITO DA COMISSÃO DE ESTATÍSTICAS DAS NAÇÕES UNIDAS E NA CONFERÊNCIA INTERNACIONAL DE ESTATÍSTICOS do TRABalHo da OIT. Qual a
IMPORTÂNCIA DESTE CONJUNTO DE ATIVIDADES PARA O TRABALHO DA INSTITUIÇÃO NO PLANO NACIONAL? Essa atuação internacional do IBGE está em conformidade com o interesse internacional que o próprio país desperta e vai ao encontro dos interesses do IBGE. Somos cada vez mais reconhecidos como uma instituição que tem algo a oferecer. Isso tem sido muito importante. Nós temos dado a nossa contribuição na cooperação Sul-Sul. Temos alguns casos bem específicos, como em São Tomé e Príncipe e Cabo Verde, onde nós ajudamos muito efetivamente na realização do Censo de população. Há também a aproximação de países desenvolvidos devido a características que são tipicamente brasileiras, como incorporar muito rapidamente a questão 
tecnológica, e isso tem motivado interesses para além dos países menos desenvolvidos. Temos motivado interesse junto aos organismos internacionais pelos avanços que tivemos, inclusive com as inovações nos sistemas de pesquisa, desses novos sistemas de informação. $O$ interesse que o próprio país desperta acaba favorecendo o interesse pelo IBGE com o reconhecimento internacional da nossa competência técnica. Isso é uma honra enorme para a Instituição, e temos que avançar no plano internacional, incorporar cada vez mais os avanços que internacionalmente são feitos e participar das discussões que são de natureza internacional e que vão alterar as recomendações da própria área.
No BRASIL VEM SE CONSOLIDANDO, GRADATIVAMENTE, A UTILIZAÇÃo DAS ESTATÍSTICAS OFICIAIS COMO INSTRUMENTOS DE APOIO À DECISÃO, PRINCIPALMENTE NO CICLO DE MONITORAMENTO E AVALIAÇÃO DAS POLÍTICAS PÚBLICAS. QUAL A IMPORTÂNCIA DA COOPERAÇÃO INTERINSTITUCIONAL NESTE PROCESSO?

É fundamental. A nossa competência é na produção da informação. O IBGE não consegue dar conta de toda a temática que ele mesmo levanta. E é justamente na cooperação interinstitucional, com os diferentes ministérios e instituições, que nós incorporamos novas temáticas e expertises que não são de domínio do IBGE, mas que são de outras instituições e que precisam ser somadas e agregadas às nossas competências para produzir essas informações. Trata-se de um processo muito rico, pois muitos aprendem com a gente e nós aprendemos muito com os outros. 